\title{
Somatic development long after the Fontan operation: Factors influencing catch-up growth
}

\author{
Masamichi Ono, MD, ${ }^{\text {a }}$ Dietmar Boethig, MD, ${ }^{\mathrm{b}}$ Heidi Goerler, MD, ${ }^{\text {a }}$ Melanie Lange, MS, ${ }^{a}$ Mechthild Westhoff-Bleck, MD, \\ and Thomas Breymann, MDa
}

Supplemental material is available online.
From the Divisions of Thoracic and Cardiovascular Surgery, ${ }^{a}$ Pediatric Cardiology and Intensive Care Medicine, ${ }^{\mathrm{b}}$ and Cardiology and Angiology, ${ }^{\mathrm{C}}$ Hannover Medical School, Hannover, Germany.

Supported in part by grants from The Uehara Memorial Foundation and The Mochida Memorial Foundation for Medical and Pharmaceutical Research.

Received for publication Jan 13, 2007; revisions received July 14, 2007; accepted for publication Aug 2, 2007.

Address for reprints: Masamichi Ono, MD, Division of Thoracic and Cardiovascular Surgery, Hannover Medical School, Carl-Neuberg-Str 1, 30625 Hannover, Germany. (E-mail: Ono.Masamichi@MHHannover.DE).

J Thorac Cardiovasc Surg 2007;134:1199-206 $0022-5223 / \$ 32.00$

Copyright () 2007 by The American Association for Thoracic Surgery

doi:10.1016/j.jtcvs.2007.08.002
Objective: As mortality and morbidity after the Fontan operation has improved, long-term outcome, including developmental aspects, have become more important. To understand the long-term effects of this operation, we followed somatic development for up to 15 years.

Methods: We evaluated 90 patients who underwent the Fontan operation between 1984 and 2004 (mean follow-up, $11.8 \pm 4.2$ years). The modified Fontan operations were atriopulmonary anastomosis $(\mathrm{n}=19)$ and total cavopulmonary connection $(\mathrm{n}=71)$. Mean age at the time of surgical intervention was $5.5 \pm 4.8$ years. Weight, height, and body mass index were evaluated preoperatively and postoperatively and given as percentiles on a normal growth curve.

Results: Postoperative weight, height, and body mass index reached the $47.2 \pm 35.6$, $37.9 \pm 30.4$, and $41.6 \pm 31.2$ percentiles, which were significantly better than preoperative values (the $21.6 \pm 25.9,25.9 \pm 25.7$, and $20.0 \pm 25.1$ percentiles). Although neither early surgical intervention nor anatomic features affected postoperative growth, early Fontan completion demonstrated better somatic development in subgroups of tricuspid atresia. Prior bidirectional Glenn shunting provided better weight gain before the Fontan operation. Prior atrioseptectomy, central shunt, and pulmonary artery reconstruction were associated with impaired somatic development. Reoperation and catheter-based intervention improved somatic development.

Conclusions: Long-term catch-up growth can be observed in patients after the Fontan operation. Early volume-unloading procedures might lead to better somatic growth. Prior atrioseptectomy, central shunt, and pulmonary artery reconstruction are associated with impaired weight and height gain, implying that the severity of the underlying diseases affects postoperative somatic development.

\section{$\mathrm{T}$} he Fontan operation was first performed in patients with tricuspid atresia as a functional repair. ${ }^{1}$ Modifications of the Fontan operation, ${ }^{2}$ staging with a bidirectional cavopulmonary shunt (ie, the bidirectional Glenn [BDG] shunt), ${ }^{3}$ and creation of fenestration in the Fontan pathway ${ }^{4}$ have reduced the mortality and morbidity associated with this operation. Today, the Fontan operation is used to treat a wide range of congenital heart defects with functional single ventricles. Improvements in preoperative management, surgical techniques, and intensive care medicine have made the Fontan operation a safe procedure at younger ages than ever before, and many reports describe excellent results from the Fontan operation in small children. ${ }^{5-7}$ The early elimination of cyanosis and volume overload in the functional single ventricle seems to be beneficial, but whether these modifications provide better postoperative somatic development is unknown. Despite the improvements in perioperative mortality, few studies have assessed the potential for postoperative growth in children with Fontan circulation. 


\author{
Abbreviations and Acronyms \\ APA $=$ atriopulmonary anastomosis \\ BDG = bidirectional Glenn \\ BMI = body mass index \\ $\mathrm{CHD}=$ congenital heart disease \\ PLE = protein-losing enteropathy \\ $\mathrm{TCPC}=$ total cavopulmonary connection
}

In the present study we evaluated somatic development over the long-term after the Fontan operation and investigated factors influencing somatic development. Moreover, the benefit of surgical and catheter-based interventions after the Fontan operation was also evaluated.

\section{Materials and Methods \\ Patients}

Between 1984 and 2004, 121 consecutive patients with functionally univentricular hearts underwent Fontan-type operations at our institution. There were 10 early deaths and 6 late failures (death or heart transplantation). Among the 105 survivors with Fontan circulation, 90 were followed up by serial measurements of weight and height. Fifteen patients are known to be alive with a Fontan circulation but could not be traced by means of regular follow-up. The characteristics of 90 patients are shown in Table 1.

The mean age at the time of the Fontan operation was $5.5 \pm 4.8$ years, ranging from 0.6 to 20 years. The mean follow-up period was $11.8 \pm 4.2$ years. Modifications of the Fontan operation included atriopulmonary anastomosis (APA; $\mathrm{n}=19$ ), performed until 1989, and total cavopulmonary connection (TCPC; $\mathrm{n}=71$ ), performed from 1988. In patients treated with TCPC, a fenestration was created at the time of Fontan completion in 18 patients, and a BDG shunt was used before the Fontan operation in 20 patients (Table 1).

\section{Data Collection of Somatic Development}

Somatic development was evaluated before and 1, 2, 5, 7, 10, 12, and 15 years after the Fontan operation by using body weight and standing height, which were related to the standard growth percentiles (normal is 50 percentile), as described previously. ${ }^{8,9}$ The body mass index (BMI) was calculated and related to the standard growth percentiles. For 20 patients who underwent BDG shunting, somatic development was also evaluated before and after BDG shunting. Data were collected from the patients' records when they were available at the Hannover Medical School. For patients followed up elsewhere, data were collected by means of fax transmission.

Informed consent was obtained from all patients, their parents, or both. The Ethics Committee of the Hannover Medical School approved the study protocol.

\section{Statistical Analysis}

Values are expressed as the mean \pm standard deviation. Data were analyzed by using the SPSS statistical software system (SPSS, Inc, Chicago, Ill). The primary outcome was determined as the weight,
TABLE 1. Patient characteristics $(n=90)$

\begin{tabular}{lrr}
\hline & \multicolumn{2}{c}{ Total $(\mathbf{n}=\mathbf{9 0})$} \\
\cline { 2 - 3 } Variable & No. & Percentage \\
\hline Diagnosis & 19 & \\
Tricuspid atresia & 30 & 21.1 \\
Predominant right ventricle & 47 & 33.3 \\
Transposition of the great arteries & 7 & 52.2 \\
Heterotaxy & 19 & 7.8 \\
Atrioventricular valve anomaly & 8 & 21.1 \\
Systemic venous anomaly & 4 & 8.9 \\
Pulmonary venous anomaly & & 4.4 \\
Palliative procedure & 13 & \\
Atrioseptectomy & 8 & 14.4 \\
Coarctation repair & 38 & 8.9 \\
Blalock-Taussig shunt & 19 & 42.2 \\
Central shunt & 10 & 21.1 \\
Pulmonary artery banding & 12 & 11.1 \\
Pulmonary artery reconstruction & & 13.3 \\
Modification of Fontan completion & 19 & \\
Atriopulmonary anastomosis & 71 & 21.1 \\
Total cavopulmonary connection & 18 & 78.9 \\
$\quad$ With fenestration & 20 & 22.0 \\
After bidirectional Glenn shunt & &
\end{tabular}

height, and BMI at the final follow-up examination. This outcome was then compared with preoperative data by using the paired Student $t$ test. The primary outcome was analyzed with a variety of categoric variables by using the unpaired Student $t$ test and with metric variables by using correlation analysis. Multivariate analysis was done by using a linear regression model to identify the risk factors that predict the primary outcome. Potential interactions among variables included in the model were analyzed by means of contingency table methods.

\section{Results}

\section{Postoperative Body Weight, Height, and BMI}

The primary outcomes determined by weight, height, and BMI at the last follow-up were the 47.2 \pm 35.6, $37.9 \pm$ 30.4 , and $41.6 \pm 31.2$ percentiles, respectively (Figure 1). These values were significantly higher than the patients' preoperative values, which were on the $21.6 \pm 25.9,25.9 \pm$ 25.7 , and $20.0 \pm 25.1$ percentiles $(P<.01$ in all variables $)$. The number of patients smaller than the fifth percentile decreased from $34(37.8 \%)$ to $13(14.4 \%)$ in weight, from $27(30.0 \%)$ to $12(13.3 \%)$ in height, and from $36(40.0 \%)$ to $9(10.0 \%)$ in BMI, whereas the number of the patients larger than the 85th percentile increased from $4(4.4 \%)$ to 17 (18.9\%) in weight, from $3(3.3 \%)$ to $9(10.0 \%)$ in height, and from $4(4.4 \%)$ to $11(12.2 \%)$ in BMI. Body weight and BMI have significantly improved by 1 year after the operation. Height has significantly improved by 2 years postoperatively (Table E1). 


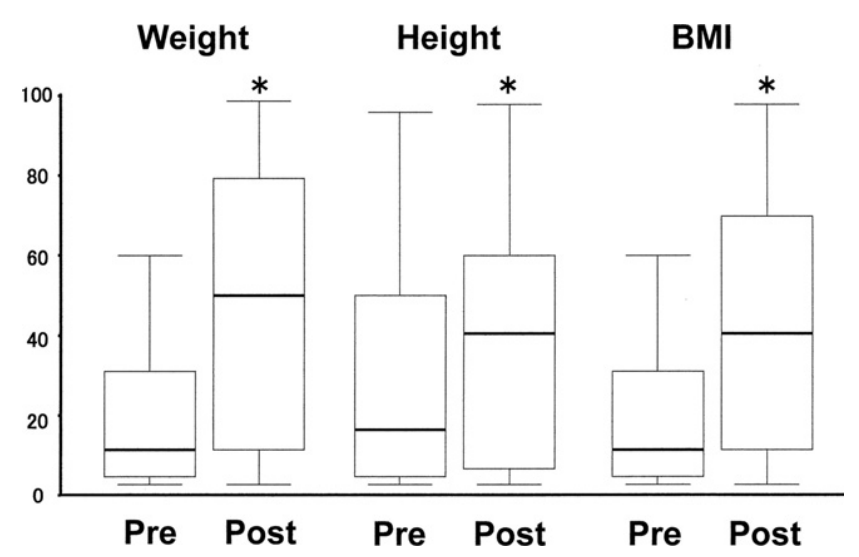

Figure 1. Box plots of preoperative and postoperative weight, height, and BMI expressed as percentiles. The central box extends from the 25th percentile to the 75th percentile; the center line marks the 50th percentile (median). The lines projecting from the box encompass the range of the data. ${ }^{*} P<.01$. BMI, Body mass index.

\section{Effect of Type of Fontan Operation}

Postoperative development of 19 patients after APA was compared with that of 71 patients treated with TCPC. Data from 3 patients treated with APA who underwent TCPC conversion 6, 7, and 14 years after the Fontan operation were excluded from this analysis for the time points after the conversion (Figure 2 and Table E2). Interestingly, the patients treated with APA showed significantly higher postoperative body weight $(P=.02)$ and BMI $(P=.007)$ than the weight of those treated with TCPC.

In the 71 patients treated with TCPC, the influences of fenestration and of having a prior BDG shunt were evaluated. As for fenestrations, they were closed in 8 patients postoperatively. We found no significant preoperative or postoperative differences between patients treated with fenestrated and nonfenestrated Fontan operations (Table E3). Concerning prior BDG shunting, patients with BDG shunts showed significantly better weight $(P=.03)$ and BMI $(P=.01)$ at the time of the Fontan operation compared with those without prior BDG shunts (Figure 3 and Table E4).

Somatic development of 20 patients with BDG shunts were evaluated before and after BDG shunting and compared with that of patients undergoing single-stage Fontan operations to analyze the effects of volume-unloading procedures (Table 2). Both BDG shunting and single-stage Fontan procedures showed improved weight, height, and BMI shortly after the procedures, and there was no statistically significant difference between the procedures with respect to postoperative catch-up.

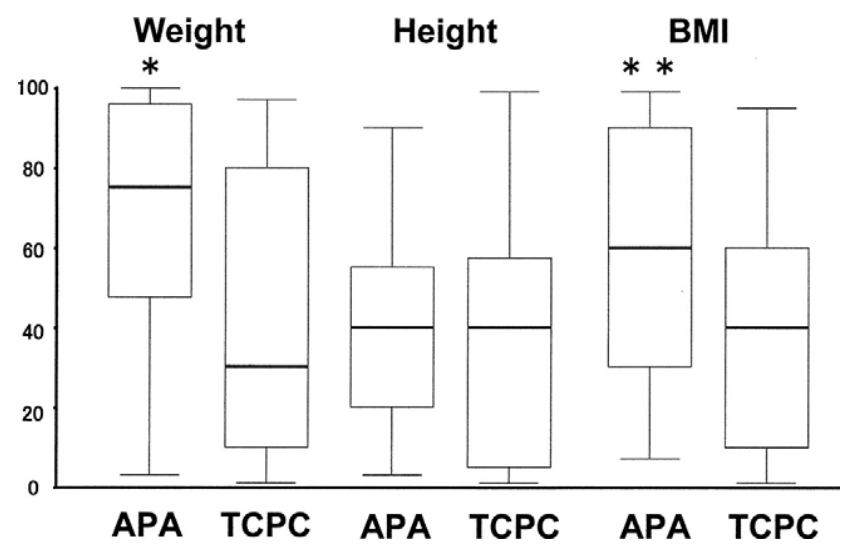

Figure 2. Box plots of postoperative weight, height, and BMI expressed as percentiles in patients with atriopulmonary anastomosis (APA) or total cavopulmonary connection (TCPC). The central box extends from the 25th percentile to the 75th percentile; the center line marks the 50th percentile (median). The lines projecting from the box encompass the range of the data. ${ }^{*} P<$ $.05,{ }^{* *} P<.01$. BMI, Body mass index.

Effect of Age at the Time of the Fontan Operation Whether young age at volume unloading (BDG shunts) or Fontan completion affects the outcome of somatic development was analyzed (Table 3). Univariate analysis showed that neither age at volume unloading nor age at the time of the Fontan operation had any significant effect on primary outcome (postoperative weight, height, and BMI). However, when the same comparison was performed in selected patients with tricuspid atresia, there was a significant negative correlation between age at the time of the Fontan operation and postoperative weight $(P=.047, R=-0.462)$ and height $(P=.037$, $R=-0.482)$. BMI had no significant correlation with age at the time of the Fontan operation in this subgroup $(P=.257)$.

\section{Preoperative and Postoperative Factors Influencing} Somatic Growth Failure

Several factors that might influence somatic development were analyzed (Table 3). Univariate analysis showed that the right ventricular dependant systemic circulation or other anatomic features were not relevant. Among palliative procedures, a prior atrioseptectomy was identified as a risk factor for impaired weight gain $(P=.02)$ and height gain $(P=.02)$ after the Fontan operation. Patients with a prior atrioseptectomy also showed significantly lower height before $(P=.001)$ surgical intervention compared with the other patients. A prior central shunt was a risk factor for impaired weight gain $(P=.03)$ and BMI $(P=.008)$. A prior pulmonary artery reconstruction was identified as a risk factor for impaired postoperative BMI $(P=.04)$. Multivariate analysis revealed that a prior central shunt was a risk factor for impaired weight gain $(P=.01)$ and BMI 


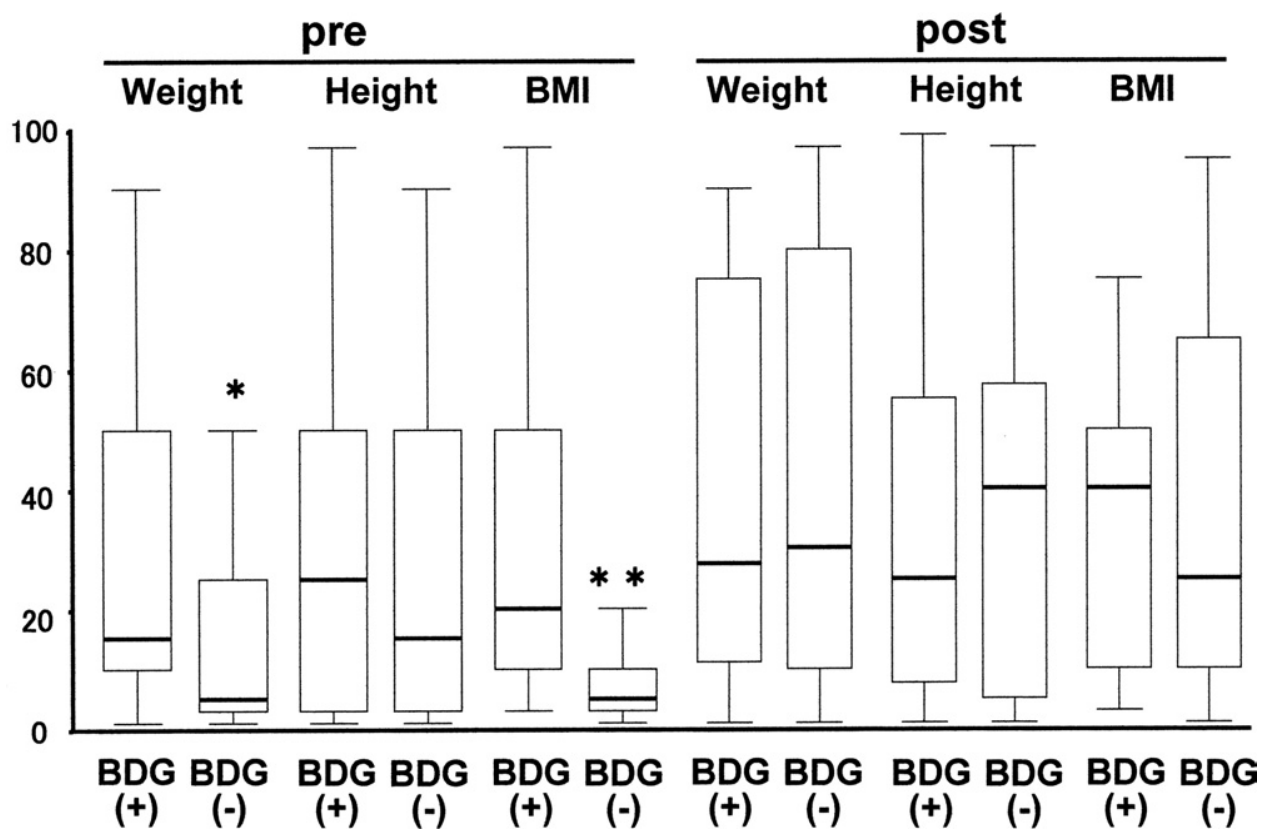

Figure 3. Box plots of preoperative and postoperative weight, height, and BMI expressed as percentiles in patients after BDG shunting or not. The central box extends from the 25th percentile to the 75 th percentile; the center line marks the 50th percentile (median). The lines projecting from the box encompass the range of the data. ${ }^{*} P<.05$, ${ }^{* *} P<.01$. BMI, Body mass index; BDG, bidirectional Glenn shunt.

$(P=.03)$. A prior coarctation repair was identified as a risk factor for impaired weight gain $(P=.02)$. The interactions between palliative procedures and the diagnosis were shown in Table 4.

Effects of Surgical and Catheter-based Interventions After the Fontan Operation

Nine reoperations were performed more than 6 months after the Fontan operation. There were 3 TCPC conversions, 3 operations to relieve subaortic stenosis, 1 aortic valve replacement, and 2 reconstructions of the Fontan pathway. The mean interval between the Fontan operation and reop- eration was $5.3 \pm 4.1$ years ( 7 months to 14 years). In these patients weight and height improved significantly after the reoperation (Table 5). Twenty-one patients had catheterbased interventions after the Fontan operation: closure of the collateral vessels (15 patients; 10 in venous collaterals and 5 in arterial collaterals) and pulmonary artery dilatation (6 patients). The mean interval between the Fontan operation and intervention was $6.1 \pm 4.4$ years $(1-15$ years $)$. These patients demonstrated improved weight gain after the procedure (Table 4). BMI was influenced neither by reoperation nor by interventions.

TABLE 2. Comparison of somatic development after the volume-unloading procedure (bidirectional Glenn shunt or single-stage Fontan operation)

\begin{tabular}{|c|c|c|c|c|c|c|c|c|c|c|c|}
\hline \multirow[b]{2}{*}{ Follow-up (y) } & \multicolumn{4}{|c|}{ BDG* } & \multicolumn{4}{|c|}{ Single-stage Fontan procedure } & \multicolumn{3}{|c|}{$P$ value } \\
\hline & $\mathbf{n}$ & Weight & Height & BMI & $\mathbf{n}$ & Weight & Height & BMI & Weight & Height & BMI \\
\hline Preoperative & 20 & $11.5 \pm 12.5$ & $21.9 \pm 22.4$ & $20.2 \pm 22.7$ & 70 & $19.0 \pm 24.8$ & $24.8 \pm 24.8$ & $16.0 \pm 21.6$ & 0.07 & 0.64 & 0.45 \\
\hline 1 & 20 & $31.9 \pm 27.5$ & $29.7 \pm 29.2$ & $39.5 \pm 34.3$ & 70 & $24.8 \pm 24.6$ & $26.8 \pm 24.9$ & $26.6 \pm 25.6$ & 0.27 & 0.66 & 0.14 \\
\hline 2 & 20 & $29.0 \pm 25.8$ & $36.2 \pm 34.7$ & $32.0 \pm 24.3$ & 70 & $30.1 \pm 28.5$ & $31.1 \pm 25.8$ & $31.8 \pm 27.9$ & 0.87 & 0.55 & 0.98 \\
\hline 5 & 20 & $30.9 \pm 24.5$ & $37.0 \pm 35.7$ & $32.7 \pm 20.5$ & 70 & $34.7 \pm 31.4$ & $34.7 \pm 29.1$ & $35.7 \pm 29.1$ & 0.56 & 0.77 & 0.62 \\
\hline 7 & 15 & $35.2 \pm 27.8$ & $40.2 \pm 35.3$ & $32.5 \pm 23.6$ & 70 & $40.1 \pm 33.2$ & $36.2 \pm 29.7$ & $40.6 \pm 30.3$ & 0.51 & 0.62 & 0.23 \\
\hline 10 & 10 & $41.3 \pm 27.9$ & $37.6 \pm 35.4$ & $43.6 \pm 26.1$ & 70 & $45.4 \pm 35.2$ & $38.6 \pm 28.6$ & $39.2 \pm 33.0$ & 0.64 & 0.91 & 0.39 \\
\hline 12 & 10 & $45.0 \pm 27.9$ & $42.1 \pm 33.6$ & $44.4 \pm 28.7$ & 70 & $45.0 \pm 37.7$ & $39.0 \pm 30.4$ & $39.2 \pm 33.0$ & 0.89 & 0.76 & 0.78 \\
\hline Last follow-up & 20 & $39.9 \pm 32.7$ & $36.7 \pm 33.7$ & $31.2 \pm 23.4$ & 70 & $49.0 \pm 36.5$ & $37.7 \pm 29.5$ & $44.5 \pm 32.8$ & 0.68 & 0.88 & 0.32 \\
\hline
\end{tabular}

*Fontan completion was performed at a mean interval of 13 months (6-22 months) for all cases. 
TABLE 3. Factor analysis influencing somatic development after the Fontan operation

\begin{tabular}{|c|c|c|c|c|c|c|c|c|c|c|}
\hline \multirow[b]{2}{*}{ Variable } & \multirow[b]{2}{*}{ n } & \multicolumn{3}{|c|}{ Weight } & \multicolumn{3}{|c|}{ Height } & \multicolumn{3}{|c|}{ BMI } \\
\hline & & Percentile & $\begin{array}{c}\text { Univariate } \\
P \text { value }\end{array}$ & $\begin{array}{l}\text { Multivariate } \\
P \text { value }\end{array}$ & Percentile & $\begin{array}{l}\text { Univariate } \\
P \text { value }\end{array}$ & $\begin{array}{l}\text { Multivariate } \\
P \text { value }\end{array}$ & Percentile & $\begin{array}{l}\text { Univariate } \\
P \text { value }\end{array}$ & $\begin{array}{c}\text { Multivariate } \\
\boldsymbol{P} \text { value }\end{array}$ \\
\hline \multicolumn{11}{|l|}{ Diagnosis } \\
\hline Tricuspid atresia & 19 & $55.1 \pm 36.2$ & .28 & & $45.0 \pm 37.9$ & .35 & & $45.4 \pm 30.7$ & .55 & \\
\hline Predominant RV & 30 & $41.3 \pm 35.4$ & .27 & & $36.6 \pm 27.3$ & .77 & & $37.6 \pm 31.4$ & .39 & \\
\hline TGA & 47 & $47.6 \pm 35.9$ & .91 & & $35.5 \pm 28.1$ & .43 & & $43.3 \pm 32.4$ & .60 & \\
\hline Heterotaxy & 7 & $45.7 \pm 43.7$ & .91 & & $35.9 \pm 23.6$ & .84 & & $44.0 \pm 43.9$ & .88 & \\
\hline AVV anomaly & 19 & $45.6 \pm 37.8$ & .82 & & $33.9 \pm 26.6$ & .52 & & $45.9 \pm 36.2$ & .50 & \\
\hline $\begin{array}{l}\text { Systemic venous } \\
\text { anomaly }\end{array}$ & 8 & $62.1 \pm 40.1$ & .22 & & $52.5 \pm 28.9$ & .16 & & $53.6 \pm 34.8$ & .26 & \\
\hline $\begin{array}{l}\text { Pulmonary venous } \\
\text { anomaly }\end{array}$ & 4 & $49.5 \pm 46.2$ & .90 & & $31.5 \pm 36.8$ & .67 & & $43.8 \pm 38.8$ & .89 & \\
\hline \multicolumn{11}{|l|}{ Palliative procedure } \\
\hline Atrioseptectomy & 13 & $27.9 \pm 29.7$ & .02 & & $23.1 \pm 21.5$ & .02 & .05 & $30.9 \pm 28.4$ & .18 & \\
\hline Coarctation repair & 8 & $24.9 \pm 33.5$ & .06 & .02 & $29.0 \pm 38.5$ & .39 & & $31.6 \pm 33.1$ & .35 & \\
\hline Blalock-Taussig shunt & 38 & $48.7 \pm 37.7$ & .74 & & $36.1 \pm 31.1$ & .64 & & $43.2 \pm 33.1$ & .68 & \\
\hline Central shunt & 19 & $31.4 \pm 31.3$ & .03 & .01 & $35.1 \pm 28.6$ & .65 & & $25.0 \pm 20.4$ & .008 & .03 \\
\hline PA banding & 10 & $48.6 \pm 34.1$ & .90 & & $42.1 \pm 35.2$ & .65 & & $41.0 \pm 31.9$ & .95 & \\
\hline PA reconstruction & 12 & $29.7 \pm 30.1$ & .07 & & $29.3 \pm 31.8$ & .29 & & $29.6 \pm 18.0$ & .04 & \\
\hline Age at unloading & & & .43 & & & .55 & & & .82 & \\
\hline $\begin{array}{l}\text { Age at Fontan } \\
\text { procedure }\end{array}$ & & & .45 & & & .53 & & & .93 & \\
\hline $\begin{array}{l}\mathrm{SaO}_{2} \text { after Fontan } \\
\text { procedure }\end{array}$ & & & .97 & & & .25 & & & .23 & \\
\hline
\end{tabular}

$R V$, Right ventricle; TGA, transposition of the great arteries; $A V V$, atrioventricular valve; $P A$, pulmonary artery; Age at unloading, age at volume unloading by bidirectional Glenn shunt or Fontan procedure; $\mathrm{SaO}_{2}$, arterial oxygen saturation.

\section{Protein-losing Enteropathy}

Three (3.3\%) patients had protein-losing enteropathy (PLE) $1.5,2$, and 4 years postoperatively. The first 2 patients showed no catch-up growth and remained at less than the first percentile both for weight and height during the follow-up. The third patient, who had PLE 4 years postoperatively, showed growth catch-up until the onset of PLE (from the 5th to the 25th percentile in height and from the 10th to the 25 th percentile in weight). After the onset of PLE, the patient's increase in height gradually slowed, and the height was at the first percentile 12 years postoperatively. Similarly, the patient's weight tempo- rarily increased to the 50th percentile but was at the first percentile 12 years postoperatively.

\section{Discussion}

Somatic development and growth in childhood are the basic overall indicators of adequate therapy for congenital heart disease (CHD). Patients with a single functional ventricle in our study showed a dramatic deceleration of weight and height gain before the Fontan operation, whereas catch-up growth occurred in both weight and height during long-term follow-up.

TABLE 4. Potential interactions between palliative procedure and diagnosis

\begin{tabular}{|c|c|c|c|c|c|c|c|c|c|c|c|c|}
\hline & TCA & RV & TGA & Het & AVV & SysV & PulV & Atrio & $\mathrm{CoA}$ & BT & CS & PAB \\
\hline Atrio & 0.06 & 0.35 & 0.77 & 1.00 & 0.46 & 0.33 & 1.00 & & & & & \\
\hline $\mathrm{CoA}$ & 0.20 & 0.43 & 0.72 & 1.00 & 0.67 & 1.00 & 1.00 & 0.01 & & & & \\
\hline BT & 0.07 & 1.00 & 0.40 & 0.45 & 0.31 & 1.00 & 0.03 & 0.11 & 1.00 & & & \\
\hline CS & 0.34 & 0.79 & 0.20 & 1.00 & 0.75 & 0.06 & 1.00 & 0.03 & 0.20 & 0.13 & & \\
\hline $\mathrm{PAB}$ & 0.11 & 0.73 & 0.32 & 1.00 & 1.00 & 0.51 & 1.00 & 0.63 & 0.005 & $0.04^{*}$ & 0.11 & \\
\hline PA reconstruction & 0.45 & 1.00 & 0.54 & 0.59 & 0.45 & 1.00 & 1.00 & 0.37 & 0.29 & 0.55 & $<0.001$ & 0.62 \\
\hline
\end{tabular}

$T C A$, Tricuspid atresia; $R V$, predominant right ventricle; TGA, transposition of the great arteries; Het, heterotaxy; $A V V$, atrioventricular valve anomaly; SysV, systemic venous anomaly; PulV, pulmonary venous anomaly; Atrio, atrioseptectomy; CoA, coarctation repair; $B T$, Blalock-Taussig shunt; $C S$, central shunt; $P A B$, pulmonary artery banding. ${ }^{*}$ Negative interaction. 
TABLE 5. Effects of intervention on somatic development after the Fontan operation

\begin{tabular}{|c|c|c|c|c|c|c|c|c|c|c|}
\hline \multirow[b]{2}{*}{ Variable } & \multirow[b]{2}{*}{$\mathbf{n}$} & \multicolumn{3}{|c|}{ Weight } & \multicolumn{3}{|c|}{ Height } & \multicolumn{3}{|c|}{ BMI } \\
\hline & & Preoperative & Postoperative & $P$ value & Preoperative & Postoperative & $P$ value & Preoperative & Postoperative & $P$ value \\
\hline Reoperation & 9 & $37.2 \pm 34.2$ & $55.4 \pm 39.1$ & 0.008 & $21.2 \pm 34.8$ & $35.3 \pm 26.0$ & 0.02 & $50.0 \pm 31.9$ & $52.8 \pm 31.3$ & 0.58 \\
\hline Intervention & 21 & $31.7 \pm 30.0$ & $36.0 \pm 32.4$ & 0.04 & $32.3 \pm 32.4$ & $34.8 \pm 33.3$ & 0.34 & $34.1 \pm 27.2$ & $37.9 \pm 29.5$ & 0.37 \\
\hline
\end{tabular}

Previous studies ${ }^{8-12}$ have reported somatic growth after the Fontan operation, but they concluded that growth remained significantly lower than in the normal population at their end point because of short follow-up periods. Our follow-up data were collected until 15 years postoperatively and provide evidence that the Fontan operation, despite its palliative nature, ${ }^{13}$ results in a significant improvement in somatic growth over the long-term. Although the pace of catch-up growth after the Fontan operation is much slower than that after biventricular repair, such as closure of a ventricular septal defect, ${ }^{14}$ corrective repair of tetralogy of Fallot, ${ }^{15}$ or switch operations to transpose the great arteries (for which catch-up growth is complete within a few years after the operation), ${ }^{16,17}$ our study shows that the Fontan operation is a reasonable surgical choice.

Similar to previous studies, ${ }^{10,11}$ we found that height was more impaired than weight after the Fontan operation. As for height, Witzel and colleagues ${ }^{18}$ described the bone and muscle development in CHD and showed evidence that patients after the Fontan operation had abnormal bone mass compared with that of the healthy population, whereas most patients with other kinds of CHD showed a normal bone mass. They speculated that reduced physical activity from birth, which hinders adequate stimulation of skeletal development, and abnormal hormonal status might be the cause of this phenomenon. As for the weight, our patients treated with APA, which is not thought to create an ideal Fontan circulation, were significantly heavier than those treated with TCPC. Mean BMI of the patients undergoing APA was on the 58th percentile, whereas the patients undergoing TCPC remained on the 37 th percentile. These results suggest that the inadequate increase of weight might be attributed to congestive heart failure that developed long after the Fontan operation. In this sense weight is not a simple indicator for adequate somatic development long after the Fontan operation.

The effects on postoperative somatic development of the modifications of the Fontan operation, such as staging with a BDG shunt or fenestration in the Fontan pathway, are of concern to surgeons. In patients with TCPC, baffle fenestration did not significantly affect somatic development. Arterial oxygen saturation after the Fontan operation did not affect somatic development. Goff and coworkers ${ }^{19}$ showed improved somatic development after fenestration closure, but this difference was due to postoperative catch-up growth. As we reported previously, fenestration is beneficial for the long-term outcome,${ }^{20}$ and these findings suggest that mild arterial desaturation is well tolerated and permits catch-up growth. On the other hand, patients who underwent BDG shunting were significantly heavier at the time of the Fontan procedure compared with the other patients. Previous reports show similar results. ${ }^{11}$ Furthermore, when BDG shunting was compared with the single-stage Fontan operation with respect to the volume-unloading procedure, BDG shunting showed similar postoperative catch-up growth. These consequences would confirm the hypothesis that it is the volume-unloading operation (BDG shunt or single-stage Fontan operation) and not completion of the Fontan operation that results in the improved hemodynamic status and permits improved growth and suggest that a staged approach to completion of the Fontan operation is important because BDG shunting can be performed in infancy.

Given that young age at the time of the Fontan operation is no longer considered a risk factor, the effects of an early establishment of Fontan circulation on somatic development is a crucial concern. It has seemed likely that the early establishment of Fontan circulation protects ventricular function, improves cyanosis, and allows an appropriate catch-up growth of the children, but there has been no consensus that this is the case. Stenbog and associates ${ }^{11}$ described significantly improved physical growth after the Fontan operation performed at a mean age 8.5 years, but Cohen and coworkers ${ }^{10}$ showed significantly decreased weight and length in children who underwent the Fontan operation at a mean age of 20 months. Ovroutski and colleagues ${ }^{9}$ showed that patients who underwent extracardiac Fontan operations before 4 years of age had better acceleration of weight gain compared with those whose operations were delayed. Although our overall results showed no significant correlation between somatic development and age at the time of the Fontan operation, an analysis in patients with tricuspid atresia revealed that young age at the time of the Fontan operation demonstrated better postoperative weight and height gain. A possible explanation of the discrepancy between this study and earlier studies is that the patients in the previous studies who underwent the Fontan operation when they were older were better candidates than younger patients. In the study by Cohen and coworkers ${ }^{10}$ showing somatic growth failure, half the in- 
fants had hypoplastic left heart syndrome requiring a Norwood procedure. In contrast, the study of Stenbog and associates ${ }^{11}$ reported on a large population of patients who would be considered ideal Fontan candidates and showed better somatic growth. Schuurmanns and colleagues ${ }^{21}$ showed that catch-up growth is correlated with the severity of the initial growth disturbance and not with age at surgical correction of isolated CHD. Furthermore, in patients with a single functional ventricle, seriousness of the heart disease might influence both preoperative and postoperative somatic growth. If comparisons were done between patient groups with heart disease of comparable severity, it might be found that the early establishment of Fontan circulation leads to better somatic growth.

Several preoperative and postoperative factors that might influence somatic development were analyzed. No anatomic feature showed any significant difference. Nevertheless, regarding palliative procedures, atrioseptectomy led to a significantly impaired height and weight gain. In this study patients treated with atrioseptectomy exhibit anatomic features of the hypoplastic left heart complex (dominant right ventricle) or double-inlet left ventricle (dominant left ventricle), which made no correlation between atrioseptectomy and a right dominant systemic ventricle. The reason why this simple procedure influenced postoperative somatic development is to be defined. We previously reported that the presence of an obstructed pulmonary venous return is a significant risk factor for the Norwood procedure. ${ }^{22}$ Latent pulmonary vascular obstructive disease by restrictive atrial septum defect in infancy might affect the post-Fontan development. Those patients who underwent central shunt or pulmonary artery reconstruction showed significantly lower weight and lower BMI. They demonstrated hypoplasia or distortion of central pulmonary arteries, suggesting that adequate development of pulmonary arteries is important for good catch-up growth after the Fontan operation. Furthermore, this subgroup of patients has previously been identified as at risk. Gentles and associates ${ }^{8}$ demonstrated, for a large number of patients, that atrioseptectomy and central shunt were risk factors for worse functional status after the Fontan operation, and Fishberger and coworkers ${ }^{23}$ demonstrated that prior atrioseptectomy and pulmonary artery reconstruction were risk factors for late tachyarrhythmia. These findings are quite in accord with our results.

Reoperations after the Fontan operation accelerated the catch-up growth in both weight and height, and interventions also accelerated postoperative weight gain. These findings indicate that patients with Fontan circulation require surgical and interventional management postoperatively for adequate catch-up growth. PLE, the cause of which is not fully understood, is also a risk factor for growth failure once it develops.
Study limitations include that 15 patients had no follow-up information available, introducing possible bias; that parental height, a significant contributor to overall somatic growth, was unavailable; that nutritional intake and daily activity patterns were not available in this retrospective analysis; and that potential confounders of poor growth, such as genetic contributions other than parental height, were not available.

In summary, catch-up growth occurred in weight, height, and BMI for the long-term after the Fontan operation. Fenestration in the Fontan pathway showed no adverse effect on postoperative somatic development. An earlier volumeunloading procedure might lead to better somatic growth. A prior atrioseptectomy, a prior central shunt, and a prior pulmonary artery reconstruction were risk factors for impaired somatic development, implying that the seriousness of the underlying cardiac malformation might deeply affect the preoperative and postoperative somatic development. Reoperations and catheter interventions accelerated somatic development after the procedures, emphasizing the necessity of constant postoperative care for catch-up growth.

We thank Dr Hikaru Matsuda, Professor Emeritus, Osaka University Graduate School of Medicine, for his support of this research.

\section{References}

1. Fontan F, Baudet E. Surgical repair of tricuspid atresia. Thorax. 1971;26:240-8.

2. de Leval MR, Kilner PK, Gewillig M, Bull C. Total cavopulmonary connection: a logical alternative to atriopulmonary connection for complex Fontan operations. Experimental studies and early clinical experience. J Thorac Cardiovasc Surg. 1988;96:682-95.

3. Bridges ND, Jonas RA, Mayer JE, Flanagan MF, Keane JF, Castaneda AR. Bidirectional cavopulmonary anastomosis as interim palliation for high-risk Fontan candidates: early results. Circulation. 1990;82(suppl): IV170-6.

4. Bridges ND, Lock JE, Castaneda AR. Baffle fenestration with subsequent transcatheter closure. Modification of the Fontan operation for patients at increased risk. Circulation. 1990;82:1681-9.

5. Kaulitz R, Ziemer G, Luhmer I, Paul T, Kallfelz HC. Total cavopulmonary anastomosis in patients less than three years of age. Ann Thorac Surg. 1995;60(suppl):S563-7.

6. Bove EL, Lloyd TR. Staged reconstruction for hypoplastic left heart syndrome. Contemporary results. Ann Surg. 1996;224:387-94.

7. Gentles TL, Mayer JE, Gauvreau K, Newburger JW, Lock JE, Kupferschmid JP, et al. Fontan operation in five hundred consecutive patients: factors influencing early and late outcome. J Thorac Cardiovasc Surg. 1997;114:376-91.

8. Gentles TL, Gauvreau K, Fishberger SB, Burnett J, Colan SD, Newburger JW, et al. Functional outcome after the Fontan operation: factors influencing late morbidity. J Thorac Cardiovasc Surg. 1997; 114:392-403.

9. Ovroutski S, Ewert P, Meskishvili VA, Stiller B, Nurunberg JH, Abdul-Khaliq H, et al. Comparison of somatic development and status of conduit after extracardiac Fontan operation in young and older children. Eur J Cardiothorac Surg. 2004;26:1073-9.

10. Cohen MI, Bush DM, Ferry RJ, Spray TL, Moshang T Jr, Wernovsky $\mathrm{G}$, et al. Somatic growth failure after the Fontan operation. Cardiol Young. 2000;10:447-57.

11. Stenbog EV, Hjortdal VE, Ravn HB, Skjaerbaek C, Sorensen KE, Hansen OK. Improvement in growth, and levels of insulin-like growth factor-I in the serum, after cavopulmonary connections. Cardiol Young. 2000;10:440-56. 
12. Day R, Denton DM, Jackson WD. Growth of children with a functionally single ventricle following palliation at moderately increased altitude. Cardiol Young. 2000;10:193-200.

13. Fontan F, Kirklin JW, Fernandez G, Costa F, Naftel DC, Tritto F, et al. Outcome after a "perfect" Fontan operation. Circulation. 1990;81:1520-36.

14. Weintraub RG, Menahem S. Early surgical closure of a large ventricular septal defect: influence on long-term growth. J Am Coll Cardiol. 1991;18:552-8.

15. Cheung MM, Davis AM, Wilkinson JL, Weintraub RG. Long term somatic growth after repair of tetralogy of Fallot: evidence for restoration of genetic growth potential. Heart. 2003;89:1340-3.

16. Levy RJ, Rosenthal A, Castaneda AR, Nadas AS. Growth after surgical repair of simple D-transposition of the great arteries. Ann Thorac Surg. 1978;25:225-30.

17. Swan JW, Weintraub RG, Radley-Smith R, Yacoub M. Long-term growth following neonatal anatomic repair of transposition of the great arteries. Clin Cardiol. 1993;16:392-6.

18. Witzel C, Sreeram N, Coburger S, Schickendantz S, Brockmeier K, Schoenau E. Outcome of muscle and bone development in congenital heart disease. Eur J Pediatr. 2006;165:168-74.
19. Goff DA, Blume ED, Gauveau K, Mayer JE, Lock JE, Jenkins KJ Clinical outcome of fenestrated Fontan patients after closure. The first 10 years. Circulation. 2000;102:2094-9.

20. Ono M, Boethig D, Goerler H, Lange M, Westhoff-Bleck M, Breymann T. Clinical outcome of patients 20 years after Fontan operation. Effect of fenestration on late outcome. Eur J Cardiothorac Surg. 2006;30:923-9.

21. Schuurmans FM, Pulles-Heintzberger CF, Gerver WJ, Kester AD, Forget PP. Long-term growth of children with congenital heart disease: a retrospective study. Acta Paediatr. 1998;87:1250-5.

22. Breymann T, Kirchner G, Blanz U, Cherlet E, Knobl H, Meyer H, et al. Results after Norwood procedure and subsequent cavopulmonary anastomosis for typical hypoplastic left heart syndrome and similar complex cardiovascular malformations. Eur J Cardiothorac Surg. 1999; 16:117-24.

23. Fishberger SB, Wernovsky G, Gentles TL, Gauvreau K, Burnett J, Mayer JE, et al. Factors that influence the development of atrial flutter after the Fontan operation. J Thorac Cardiovasc Surg. 1997 113:80-6.

Access to The Journal of Thoracic and Cardiovascular Surgery Online is reserved for print subscribers!

Full-text access to The Journal of Thoracic and Cardiovascular Surgery Online is available for all print subscribers. To activate your individual online subscription, please visit The Journal of Thoracic and Cardiovascular Surgery Online, point your browser to http://www.mosby.com/itcvs, follow the prompts to activate your online access, and follow the instructions. To activate your account, you will need your subscriber account number, which you can find on your mailing label (note: the number of digits in your subscriber account number varies from 6 to 10). See the example below in which the subscriber account number has been circled:

\section{Sample mailing label}

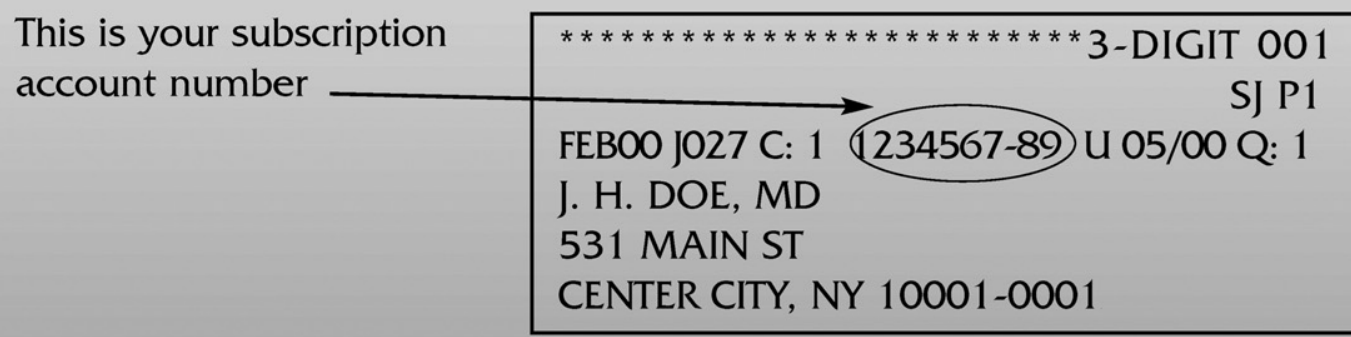

Personal subscriptions to The Journal of Thoracic and Cardiovascular Surgery Online are for individual use only and may not be transferred. Use of The Journal of Thoracic and Cardiovascular Surgery Online is subject to agreement to the terms and conditions as indicated online. 
TABLE E1. Somatic development after the Fontan operation

\begin{tabular}{lcccc}
\hline Follow-up (y) & $\mathbf{n}$ & Weight (percentile) & Height (percentile) & BMI (percentile) \\
\hline Preoperative & 90 & $21.6 \pm 25.9$ & $25.9 \pm 25.7$ & $20.0 \pm 25.1$ \\
1 & 90 & $26.0 \pm 25.3^{*}$ & $28.3 \pm 26.9$ & $28.4 \pm 25.6 \dagger$ \\
2 & 89 & $29.9 \pm 28.3^{\dagger}$ & $31.7 \pm 27.8^{*}$ & $30.1 \pm 26.6^{\dagger}$ \\
5 & 88 & $33.9 \pm 30.6^{\dagger}$ & $35.2 \pm 30.2^{\dagger}$ & $33.6 \pm 27.7^{\dagger}$ \\
7 & 81 & $39.0 \pm 32.4^{\dagger}$ & $35.4 \pm 30.2^{\dagger}$ & $40.6 \pm 29.3^{\dagger}$ \\
10 & 80 & $45.4 \pm 34.3^{\dagger}$ & $38.5 \pm 28.8^{\dagger}$ & $41.1 \pm 32.0^{\dagger}$ \\
12 & 67 & $45.8 \pm 37.2^{\dagger}$ & $38.5 \pm 30.4^{\dagger}$ & $42.2 \pm 31.9^{\dagger}$ \\
15 & 42 & $52.6 \pm 36.9^{\dagger}$ & $35.3 \pm 29.9^{\dagger}$ & \\
At last follow-up & 90 & $47.2 \pm 35.6^{\dagger}$ & $37.9 \pm 30.4^{\dagger}$ & \\
\hline
\end{tabular}

$B M I$, Body mass index. ${ }^{*} P<0.05$ and ${ }^{\dagger} P<.01$ versus preoperative.

TABLE E2. Comparison of somatic development with type of Fontan operation

\begin{tabular}{|c|c|c|c|c|c|c|c|c|c|c|c|}
\hline \multirow[b]{2}{*}{ Follow-up (y) } & \multicolumn{4}{|c|}{ APA } & \multicolumn{4}{|c|}{ TCPC } & \multicolumn{3}{|c|}{$P$ value } \\
\hline & $\mathbf{n}$ & Weight & Height & BMI & $\mathbf{n}$ & Weight & Height & BMI & Weight & Height & BMI \\
\hline Preoperative & 19 & $25.8 \pm 30.0$ & $22.7 \pm 21.1$ & $20.4 \pm 25.9$ & 71 & $20.5 \pm 24.9$ & $26.7 \pm 26.9$ & $19.9 \pm 25.1$ & .43 & .55 & .94 \\
\hline 1 & 19 & $28.5 \pm 25.1$ & $24.3 \pm 23.1$ & $34.0 \pm 25.9$ & 71 & $25.3 \pm 25.5$ & $29.3 \pm 27.8$ & $27.5 \pm 25.7$ & .63 & .47 & .46 \\
\hline 2 & 19 & $30.3 \pm 28.6$ & $23.8 \pm 21.7$ & $39.5 \pm 33.8$ & 71 & $29.8 \pm 28.4$ & $33.8 \pm 29.0$ & $28.1 \pm 24.7$ & .95 & .16 & .27 \\
\hline 5 & 19 & $36.3 \pm 30.7$ & $28.6 \pm 24.7$ & $46.2 \pm 31.1$ & 71 & $33.2 \pm 30.8$ & $37.0 \pm 31.5$ & $30.5 \pm 26.2$ & .70 & .29 & .05 \\
\hline 7 & $18^{*}$ & $44.2 \pm 33.0$ & $29.8 \pm 26.4$ & $47.9 \pm 27.8$ & 62 & $37.9 \pm 32.4$ & $37.4 \pm 31.3$ & $37.2 \pm 29.0$ & .47 & .35 & .25 \\
\hline 10 & $17^{*}$ & $57.7 \pm 34.6$ & $40.2 \pm 27.8$ & $39.1 \pm 30.2$ & 61 & $42.9 \pm 33.9$ & $38.6 \pm 29.5$ & $41.0 \pm 32.3$ & .12 & .84 & .84 \\
\hline 12 & $17^{*}$ & $61.3 \pm 36.7$ & $42.9 \pm 30.7$ & $52.8 \pm 33.5$ & 61 & $39.9 \pm 36.9$ & $37.9 \pm 30.7$ & $36.2 \pm 30.2$ & .04 & .56 & .11 \\
\hline 15 & $15^{*}$ & $68.5 \pm 34.3$ & $43.3 \pm 29.2$ & $55.1 \pm 33.0$ & 27 & $43.0 \pm 35.9$ & $32.4 \pm 31.4$ & $41.4 \pm 27.6$ & .03 & .28 & .28 \\
\hline Last follow-up & 19 & $64.7 \pm 34.5$ & $38.9 \pm 27.3$ & $58.2 \pm 31.2$ & 71 & $42.6 \pm 34.7$ & $37.6 \pm 31.3$ & $36.8 \pm 29.4$ & .02 & .87 & .007 \\
\hline
\end{tabular}

$B M I$, Body mass index. *Patients converted from atriopulmonary anastomosis to total cavopulmonary connection were excluded.

TABLE E3. Comparison of somatic development with and without fenestration

\begin{tabular}{|c|c|c|c|c|c|c|c|c|c|c|c|}
\hline \multirow[b]{2}{*}{ Follow-up (y) } & \multicolumn{4}{|c|}{ Fenestration } & \multicolumn{4}{|c|}{ No fenestration } & \multicolumn{3}{|c|}{$P$ value } \\
\hline & $\mathbf{n}$ & Weight & Height & BMI & $\mathbf{n}$ & Weight & Height & BMI & Weight & Height & BMI \\
\hline Preoperative & 18 & $17.9 \pm 19.7$ & $24.4 \pm 25.4$ & $24.4 \pm 25.4$ & 53 & $21.3 \pm 26.5$ & $27.5 \pm 27.6$ & $18.4 \pm 25.8$ & .62 & .68 & .40 \\
\hline 1 & 18 & $22.1 \pm 22.7$ & $27.9 \pm 29.3$ & $29.5 \pm 28.5$ & 53 & $26.4 \pm 26.5$ & $29.8 \pm 27.6$ & $26.8 \pm 24.8$ & .54 & .80 & .72 \\
\hline 2 & 18 & $29.0 \pm 27.5$ & $29.0 \pm 27.9$ & $25.5 \pm 24.5$ & 53 & $30.1 \pm 28.9$ & $35.5 \pm 29.4$ & $29.5 \pm 24.9$ & .89 & .42 & .48 \\
\hline 5 & 18 & $26.5 \pm 26.2$ & $29.1 \pm 26.4$ & $19.9 \pm 22.5$ & 53 & $35.4 \pm 32.0$ & $39.6 \pm 32.8$ & $34.0 \pm 26.6$ & .30 & .22 & .69 \\
\hline 7 & 12 & $26.5 \pm 23.0$ & $26.5 \pm 25.4$ & $32.4 \pm 33.1$ & 51 & $40.4 \pm 33.8$ & $39.8 \pm 32.1$ & $38.2 \pm 28.4$ & .20 & .20 & .59 \\
\hline 10 & 10 & $37.0 \pm 29.1$ & $32.6 \pm 21.6$ & $42.0 \pm 33.5$ & 51 & $43.9 \pm 34.8$ & $39.7 \pm 30.7$ & $40.8 \pm 32.4$ & .58 & .51 & .92 \\
\hline 12 & 10 & $30.6 \pm 29.5$ & $30.3 \pm 20.5$ & $46.0 \pm 35.1$ & 51 & $40.9 \pm 37.8$ & $39.2 \pm 32.2$ & $35.2 \pm 29.9$ & .56 & .43 & .56 \\
\hline Last follow-up & 18 & $34.8 \pm 29.5$ & $30.9 \pm 26.5$ & $32.4 \pm 27.5$ & 53 & $45.2 \pm 36.2$ & $39.9 \pm 32.7$ & $38.3 \pm 30.1$ & .23 & .29 & .47 \\
\hline
\end{tabular}

$B M I$, Body mass index. 
TABLE E4. Comparison of somatic development after the bidirectional Glenn operation

\begin{tabular}{|c|c|c|c|c|c|c|c|c|c|c|c|}
\hline \multirow[b]{2}{*}{ Follow-up (y) } & \multicolumn{4}{|c|}{ After BDG } & \multicolumn{4}{|c|}{ Not after BDG } & \multicolumn{3}{|c|}{$P$ value } \\
\hline & $\mathbf{n}$ & Weight & Height & BMI & $\mathbf{n}$ & Weight & Height & BMI & Weight & Height & BMI \\
\hline Preoperative & 20 & $30.5 \pm 28.5$ & $29.6 \pm 29.3$ & $34.2 \pm 31.4$ & 51 & $16.5 \pm 22.3$ & $25.6 \pm 26.1$ & $14.3 \pm 19.8$ & .03 & .58 & .01 \\
\hline 2 & 20 & $29.3 \pm 28.4$ & $33.9 \pm 34.5$ & $25.4 \pm 22.7$ & 51 & $30.0 \pm 28.7$ & $33.8 \pm 26.9$ & $29.4 \pm 25.7$ & .93 & .99 & .56 \\
\hline 5 & 20 & $30.5 \pm 27.8$ & $36.8 \pm 34.5$ & $27.2 \pm 22.4$ & 51 & $34.2 \pm 31.9$ & $37.0 \pm 30.5$ & $31.9 \pm 27.8$ & .66 & .98 & .53 \\
\hline 7 & 12 & $32.6 \pm 27.6$ & $31.2 \pm 34.0$ & $37.6 \pm 25.4$ & 51 & $39.2 \pm 33.6$ & $30.8 \pm 34.0$ & $37.1 \pm 30.3$ & .53 & .45 & .96 \\
\hline Last follow-up & 20 & $39.9 \pm 32.7$ & $36.7 \pm 33.7$ & $31.2 \pm 23.4$ & 53 & $43.7 \pm 35.7$ & $38.0 \pm 30.7$ & $39.0 \pm 31.4$ & .68 & .88 & .32 \\
\hline
\end{tabular}

$B M I$, Body mass index. 